\title{
Sex differences in cardiovascular function during submaximal exercise in humans
}

\author{
Courtney M Wheatley ${ }^{1}$, Eric M Snyder ${ }^{2}$, Bruce D Johnson ${ }^{1}$ and Thomas P Olson ${ }^{*}$
}

\begin{abstract}
Differences in cardiovascular function between sexes have been documented at rest and maximal exercise. The purpose of this study was to examine the sex differences in cardiovascular function during submaximal constant-load exercise, which is not well understood.

Thirty-one male and 33 female subjects completed nine minutes moderate and nine minutes vigorous intensity submaximal exercise ( 40 and $75 \%$ of peak watts determined by maximal exercise test). Measurements included: intra-arterial blood pressure (SBP and DBP), cardiac index $\left(\mathrm{Q}_{1}\right)$, heart rate $(\mathrm{HR})$, oxygen consumption $\left(\mathrm{VO}_{2}\right)$ and arterial catecholamines (epinephrine $=\mathrm{EPI}$ and norepinephrine $=\mathrm{NE}$ ), and blood gases. Mean arterial pressure $(\mathrm{MAP})$, stroke volume index $\left(\mathrm{SV}_{1}\right)$, systemic vascular resistance index $\left(\mathrm{SV} \mathrm{R}_{1}\right)$, arterial oxygen content $\left(\mathrm{CaO}_{2}\right)$, arterial to venous $\mathrm{O}_{2}$ difference $\left(\mathrm{AVO}_{2}\right)$ and systemic oxygen transport (SOT) were calculated.

At rest and during submaximal exercise $\mathrm{Q}_{1}, \mathrm{SV}, \mathrm{SBP}, \mathrm{MAP}, \mathrm{NE}, \mathrm{CaO}_{2}$, and $\mathrm{SOT}$ were lower in females compared to males. $\mathrm{VO}_{2}, \mathrm{AVO}_{2}$, EPI were lower in females throughout exercise. When corrected for wattage, females had a higher $\mathrm{Q}, \mathrm{HR}, \mathrm{SV}, \mathrm{VO}_{2}$ and $\mathrm{AVO}_{2}$ despite lower energy expenditure and higher mechanical efficiency.

This study demonstrates sex differences in the cardiovascular response to constant-load submaximal exercise. Specifically, females presented limitations in cardiac performance in which they are unable to compensate for reductions in stroke volume through increases in HR, potentially a consequence of a female's blunted sympathetic response and higher vasodilatory state. Females demonstrated greater cardiac work needed to meet the same external work demand, and relied on increased peripheral oxygen extraction, lower energy expenditure and improvements in mechanical efficiency as compensatory mechanisms.
\end{abstract}

Keywords: Cardiac output; Arterial pressure; Systemic vascular resistance; Catecholamines; Energy expenditure

\section{Background}

Control of the cardiovascular system is critical for homeostasis and to respond to stresses such as physical activity (Rowell 1993). During exercise, a number of physiologic adjustments must occur to provide the necessary supply of oxygen and nutrients to meet the demands of muscular work dictated by the task presented (Rowell 1993). As such, the cardiovascular adjustments to exercise have been studied extensively to provide general guidelines regarding the normal or anticipated responses of various physiologic systems.

Numerous physiologic differences exist between men and women including: height, weight, body composition

\footnotetext{
*Correspondence: olson.thomas2@mayo.edu

'Division of Cardiovascular Diseases, Mayo Clinic, 200 1st Street, SW, Rochester, MN 55905, USA

Full list of author information is available at the end of the article
}

(including fat and lean muscle mass), as well as differences in hormones (e.g. estrogen, progesterone, testosterone, etc.) and hemoglobin levels (Charkoudian and Joyner 2004). With regards to exercise capacity, the enhanced capacity for increased maximal oxygen uptake noted in males is often cited to explain the heightened physical performance in males. However, when individuals are matched for age, height, and lean muscle mass, there remains considerable differences in the cardiovascular response to exercise according to sex, the reasons for which remain less clear (Charkoudian and Joyner 2004). Previous work suggests differences exist in the mechanisms contributing to enhancement of cardiac performance during aerobic exercise between sexes, where females have demonstrated a blunted increase in ejection fraction with exercise (Adams et al. 1987; Higginbotham et al. 1984; Kuo et al. 1987), and unlike

\section{实 Springer}


men, women demonstrated no increase in stroke volume with exercise training (Spina et al. 1993). Further, women have demonstrated a slower age associated decline in HR reserve with age; in contrast, men have a shown an increase in end diastolic volume index and stroke work index with age (Fleg et al. 1995). Taken together it has been suggested that men have a greater reliance on preload and enhanced use of the FrankStarling mechanism whereas females rely on heart rate to increase cardiac output. To date, the majority of this previous work has been documented at rest and maximal exercise; leaving a major paucity of data regarding the differences in cardiovascular response to submaximal constant-load exercise between men and women, as findings have primarily been drawn from submaximal workloads during a maximal exercise test (Fleg et al. 1995; Sullivan et al. 1991). As such a number of questions remain unanswered, including: 1) do the reductions in cardiac function demonstrated at peak exercise in females remain at submaximal intensities, 2) what are the underlying mechanisms leading to differences in the cardiovascular response to exercise across sex boundaries, 3) what compensatory mechanisms do females rely on in an attempt to ameliorate limitations, and 4) do the known differences between sexes become more apparent or dissipate when the individuals are non-sedentary (exercising $>3$ times/week).

Therefore, the purpose of this study was to examine the differences in the cardiovascular response to constant-load submaximal exercise between men and women. To this end, we examined cardiac output and its subcomponents (stroke volume and heart rate) as well as the intra-arterial blood pressure and catecholamine responses to exercise in healthy men and women at rest and during moderate and vigorous intensity constant-load exercise. We hypothesized that despite similar cardiac output during moderate submaximal exercise stroke volume index would be higher in men whereas females would demonstrate higher HR for that given workload. In contrast during vigorous exercise, females would present reduced cardiac output due to an inability to accommodate the added demand via increased HR. Further, we expected males to demonstrate elevated SBP and MAP in comparison to female subjects.

\section{Results}

\section{Participant characteristics}

Table 1 details the demographic characteristics of the participants. Sixty-four healthy participants, male $(\mathrm{n}=31)$ and female $(\mathrm{n}=33)$, were recruited for this study. Although there was no difference in age across sexes $(\mathrm{p}=0.44)$, as expected the males were taller, heavier, and had a higher BMI and BSA compared to the female participants $(\mathrm{p}<0.01$ for all).
Table 1 Participant characteristics

\begin{tabular}{lcccc}
\hline & All & Male & Female & p-value \\
\hline Number & 64 & 31 & 33 & \\
Age & $29.0 \pm 0.7$ & $29.6 \pm 1.0$ & $28.4 \pm 1.1$ & 0.44 \\
Height $(\mathrm{m})$ & $1.7 \pm 0.0$ & $1.8 \pm 0.0$ & $1.7 \pm 0.0$ & $<0.001$ \\
Weight $(\mathrm{kg})$ & $73.0 \pm 1.7$ & $82.3 \pm 1.8$ & $64.2 \pm 1.8$ & $<0.001$ \\
BMI $\left(\mathrm{kg} / \mathrm{m}^{2}\right)$ & $24.1 \pm 0.4$ & $25.4 \pm 0.6$ & $22.8 \pm 0.5$ & 0.002 \\
BSA $\left(\mathrm{m}^{2}\right)$ & $1.9 \pm 0.0$ & $2.0 \pm 0.0$ & $1.7 \pm 0.0$ & $<0.001$ \\
VO ${ }_{2}$ max $(\mathrm{mL} / \mathrm{min} / \mathrm{Kg})$ & $35.0 \pm 0.9$ & $39.0 \pm 1.3$ & $31.2 \pm 1.0$ & $<0.001$ \\
VO ${ }_{2}$ max $(\%$ pred.) & $96.1 \pm 15.7$ & $95.4 \pm 15.5$ & $96.8 \pm 16.2$ & 0.73 \\
Peak workload $(\mathrm{W})_{220.0 \pm 7.4} 252.1 \pm 10.0$ & $189.8 \pm 8.1$ & $<0.001$ \\
\hline
\end{tabular}

$B M I$, body mass index; $B S A$, body surface area; $\mathrm{VO}_{2} \max$, maximal oxygen uptake. Data are presented as mean \pm SD. P-value $=$ Students $T$-test male vs. female.

\section{Sex differences in cardiovascular function at rest}

Table 2 highlights the cardiovascular function according to sex during the pre-exercise rest period while individuals were seated upright on the cycle ergometer. At rest there was no difference in $\mathrm{VO}_{2}(\mathrm{p}=0.44)$; however, the male participants demonstrated a higher $\mathrm{Q}_{\mathrm{I}}(\mathrm{p}=0.03)$ mediated by a higher $\mathrm{SV}_{\mathrm{I}}(\mathrm{p}=0.01)$. There was trend for the female participants to have a higher HR $(p=0.06)$. The male participants also demonstrated a higher SBP $(\mathrm{p}<0.01)$ with no difference in DBP $(\mathrm{p}=0.13)$. Although the SBP measured via the arterial catheter suggests some of the males may have been mildly hypertensive, the cuff auscultation measurement $(118 \pm 11)$ clarifies they were normotensive and the elevated SBP was likely due to the placement of the arterial catheter and that the measurements were taken pre-exercise not in a true resting condition (Wheatley et al. 2013). The higher SBP in the male participants contributed to an elevated MAP $(p=0.02)$. Since MAP and $Q_{I}$ were both elevated in males, there was no difference in $S_{V}$ between the two sexes $(p=0.83)$. Figures 1 and 2 show data detailing the three measurement time points during the resting period for all cardiovascular measures. Male participants demonstrated greater circulating NE levels $(p=0.03)$ while EPI levels were similar $(p=0.19)$ when compared to their female counterparts. Although the partial pressure of oxygen $\left(\mathrm{PaO}_{2}\right)$ was similar between sexes, the lower hemoglobin $(\mathrm{Hb})$ concentration reduced the arterial oxygen content $\left(\mathrm{CaO}_{2}\right)$ and systemic oxygen transport (SOT) in female participants $(\mathrm{p}<0.01$ for $\mathrm{Hb}$, $\mathrm{CaO}_{2}$ and $\mathrm{p}=0.02$ for SOT). Additionally, the partial pressure of carbon dioxide $\left(\mathrm{PaCO}_{2}\right)$ was higher in the male participants $(\mathrm{p}=0.02)$.

\section{Sex differences in cardiovascular function during moderate intensity constant-load exercise}

Table 3 describes the cardiovascular response to moderate intensity steady-state exercise among males and females. The male participants demonstrated a higher 
Table 2 Resting physiologic measures

\begin{tabular}{|c|c|c|c|c|}
\hline & All & Male & Female & p-value \\
\hline \multicolumn{5}{|l|}{ Cardiovascular } \\
\hline $\mathrm{VO}_{2}(\mathrm{~mL} / \mathrm{min})$ & $274.6 \pm 75.8$ & $317.6 \pm 76.3$ & $234.1 \pm 48.7$ & $<0.01$ \\
\hline $\mathrm{VCO}_{2}(\mathrm{~mL} / \mathrm{min})$ & $218.2 \pm 76.0$ & $259.8 \pm 78.6$ & $233.9 \pm 47.9$ & $<0.01$ \\
\hline $\mathrm{VO}_{2}(\mathrm{~mL} / \mathrm{kg} / \mathrm{min})$ & $3.75 \pm 1.27$ & $3.81 \pm 0.83$ & $3.67 \pm 0.77$ & 0.44 \\
\hline $\mathrm{Q}_{1}\left(\mathrm{~L} / \mathrm{min} / \mathrm{m}^{2}\right)$ & $3.2 \pm 0.8$ & $3.5 \pm 0.9$ & $3.0 \pm 0.6$ & 0.03 \\
\hline $\mathrm{SV} \mathrm{V}_{1}\left(\mathrm{~mL} / \mathrm{m}^{2}\right)$ & $41.6 \pm 15.3$ & $46.5 \pm 18.2$ & $37.1 \pm 10.1$ & 0.01 \\
\hline $\mathrm{HR}$ (bts/min) & $81.0 \pm 11.3$ & $77.8 \pm 12.3$ & $84.1 \pm 9.4$ & 0.06 \\
\hline $\mathrm{AVO}_{2}$ Difference $(\mathrm{mL} \mathrm{O} / 100 \mathrm{~mL}$ blood) & $4.7 \pm 1.3$ & $4.8 \pm 1.4$ & $4.6 \pm 1.2$ & 0.52 \\
\hline $\mathrm{SBP}(\mathrm{mm} \mathrm{Hg})$ & $134.9 \pm 17.2$ & $141.5 \pm 14.5$ & $128.7 \pm 17.5$ & $<0.01$ \\
\hline $\mathrm{DBP}(\mathrm{mm} \mathrm{Hg})$ & $79.3 \pm 11.6$ & $82.0 \pm 11.6$ & $76.7 \pm 11.2$ & 0.13 \\
\hline MAP $(\mathrm{mm} \mathrm{Hg})$ & $97.8 \pm 12.3$ & $101.8 \pm 11.5$ & $94.0 \pm 11.9$ & 0.02 \\
\hline SVRI $\left(\right.$ dyn* $\left.\mathrm{sec} / \mathrm{cm}^{5} / \mathrm{m}^{2}\right)$ & $255.4 \pm 715.2$ & $2544.30 . \pm 807.1$ & $2564.5 .9 \pm 629.4$ & 0.83 \\
\hline Hemoglobin (g/dL) & $14.4 \pm 1.4$ & $15.4 \pm 1.2$ & $13.5 \pm 0.8$ & $<0.01$ \\
\hline SOT $\left(\mathrm{mL} / \mathrm{min} / \mathrm{m}^{2}\right)$ & $624.7 \pm 184.1$ & $709.50 \pm 212.3$ & $544.2 \pm 104.0$ & 0.02 \\
\hline $\operatorname{RPE}\left(\mathrm{mL} / \mathrm{min} / \mathrm{m}^{2}\right)$ & $6.4 \pm 0.0$ & $6.1 \pm 0.4$ & $6.0 \pm 0.0$ & 0.31 \\
\hline \multicolumn{5}{|l|}{ Blood gases } \\
\hline $\mathrm{PaO}_{2}(\mathrm{~mm} \mathrm{Hg})$ & $100.7 \pm 11.7$ & $102.3 \pm 11.2$ & $99.0 \pm 10.9$ & 0.25 \\
\hline $\mathrm{PaCO}_{2}(\mathrm{~mm} \mathrm{Hg})$ & $35.1 \pm 4.2$ & $35.5 \pm 4.9$ & $34.8 \pm 3.5$ & 0.02 \\
\hline $\mathrm{CaO}_{2}(\mathrm{~mL} / 100 \mathrm{~mL})$ & $19.14 \pm 1.8$ & $20.4 \pm 1.6$ & $17.9 \pm 1.1$ & $<0.01$ \\
\hline \multicolumn{5}{|l|}{ Catecholamines \& lactate } \\
\hline Epinephrine (pg/mL) & $95.8 \pm 53.5$ & $104.8 \pm 38.3$ & $87.3 \pm 64.1$ & 0.19 \\
\hline Norepinephrine (pg/mL) & $297.9 \pm 86.7$ & $322.7 \pm 93.8$ & $274.7 \pm 73.6$ & 0.03 \\
\hline Lactate (mM) & $0.77 \pm 0.37$ & $0.78 \pm 0.26$ & $0.75 \pm 0.45$ & 0.68 \\
\hline
\end{tabular}

$\mathrm{VO}_{2}$, volume of oxygen consumption; $\mathrm{Q}_{1}$, cardiac index; $\mathrm{SV}_{1}$, stroke volume index; $\mathrm{HR}$, heart rate; $\mathrm{AVO}_{2}$ difference, arterial to venous $\mathrm{O}_{2}$ difference; $\mathrm{SBP}$, systolic blood pressure (direct arterial); DBP, diastolic blood pressure (direct arterial); MAP, mean arterial pressure (direct arterial); SVR, systematic vascular resistance index; SOT, systematic oxygen transport; RPE, rating of perceived exertion; $\mathrm{PaO} 2$, arterial partial pressure of oxygen; $\mathrm{PaCO}_{2}$, arterial partial pressure of carbon dioxide; $\mathrm{CaO}_{2}$, arterial oxygen content. Data are presented as mean $\pm \mathrm{SD}$ for 3 measurement timepoints during the resting period. $\mathrm{P}$-value $=\mathrm{Students} T$-test male vs. female.

$\mathrm{VO}_{2}(\mathrm{p}<0.01)$ with an elevated $\mathrm{Q}_{\mathrm{I}}(\mathrm{p}<0.01)$ mediated by a higher $\mathrm{SV}_{\mathrm{I}}(\mathrm{p}<0.01)$. During moderate intensity exercise, the reduced oxygen carrying capacity, due to lower $\mathrm{Hb}$ levels $(\mathrm{p}<0.01)$ in female participants was sufficient to result in lower oxygen consumption and contributed to a reduced SOT mediated by a lower $\mathrm{CaO}_{2}$ and $\mathrm{Q}_{\mathrm{I}}$. Similar to at rest, the $\mathrm{PaCO}_{2}$ was higher in the male participants $(\mathrm{p}<0.01)$. The female participants also demonstrated a trend for higher HR $(p=0.07)$, although this difference was not large enough to compensate for the lower $\mathrm{SV}_{\mathrm{I}}$ and subsequently reduced $\mathrm{Q}_{\mathrm{I}}$ in females. The male participants demonstrated a higher SBP $(\mathrm{p}<0.01)$ which contributed to higher MAP $(p<0.01)$ as there was no difference in DBP between males and females $(\mathrm{p}=0.11)$. As was seen at rest, the differential response between males and females in $\mathrm{Q}_{\mathrm{I}}$ and MAP did not result in a difference in $\mathrm{SVR}_{\mathrm{I}}$ between sexes $(\mathrm{p}=0.41)$. Both $\mathrm{NE}$ and EPI levels were higher in the male participants $(\mathrm{p}<0.01)$. Blood lactate increased from baseline in both groups and stabilized over the nine minute bout. Figures 1 and 2 detail data collected for all three measurement time points the moderate intensity constant-load exercise period for all cardiovascular measures, blood lactate measured for all three time points is provided in Figure 3.

\section{Sex differences in cardiovascular function during vigorous intensity constant-load exercise}

Table 4 details the differences in cardiovascular function at vigorous intensity constant-load exercise between sexes. Despite being at a matched relative workload, the male participants demonstrated a higher $\mathrm{VO}_{2}(\mathrm{p}<0.01)$. The male participants also demonstrated a higher $\mathrm{Q}_{\mathrm{I}}(\mathrm{p}<0.01)$ mediated by a higher $\mathrm{SV}_{\mathrm{I}}(\mathrm{p}<0.01)$ since there was no difference between the groups for HR $(p=0.95) . \mathrm{CaO}_{2}$ and SOT again remained lower and likely contributed to the lower $\mathrm{VO}_{2}$ in female participants $(\mathrm{p}<0.01)$. Again, $\mathrm{PaCO}_{2}$ was higher in the male participants $(\mathrm{p}<0.01)$. Similar to the moderate intensity workload, the male participants demonstrated a higher SBP $(\mathrm{p}<0.01)$ which contributed to a higher MAP $(\mathrm{p}<0.01)$ since there was again no 
A

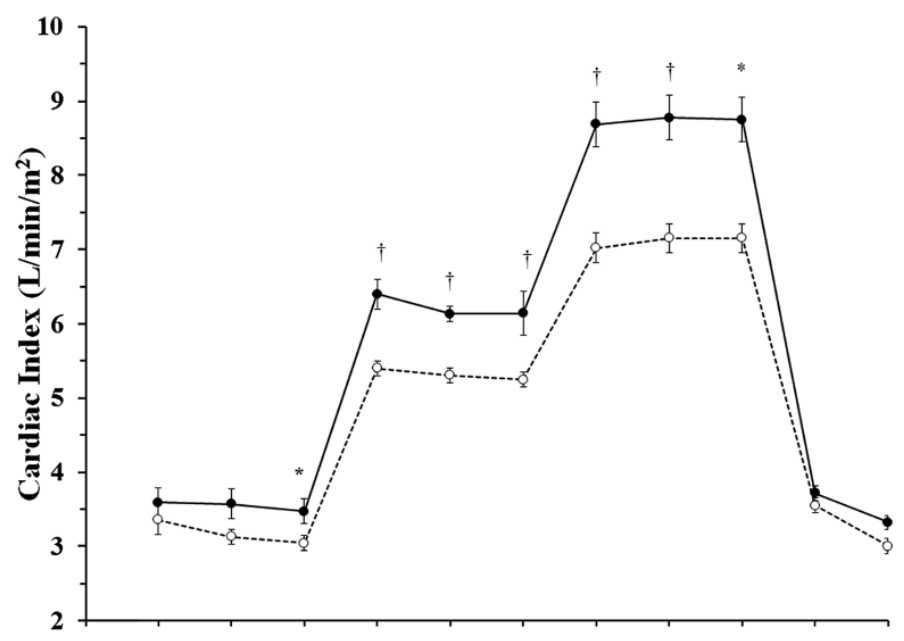

B

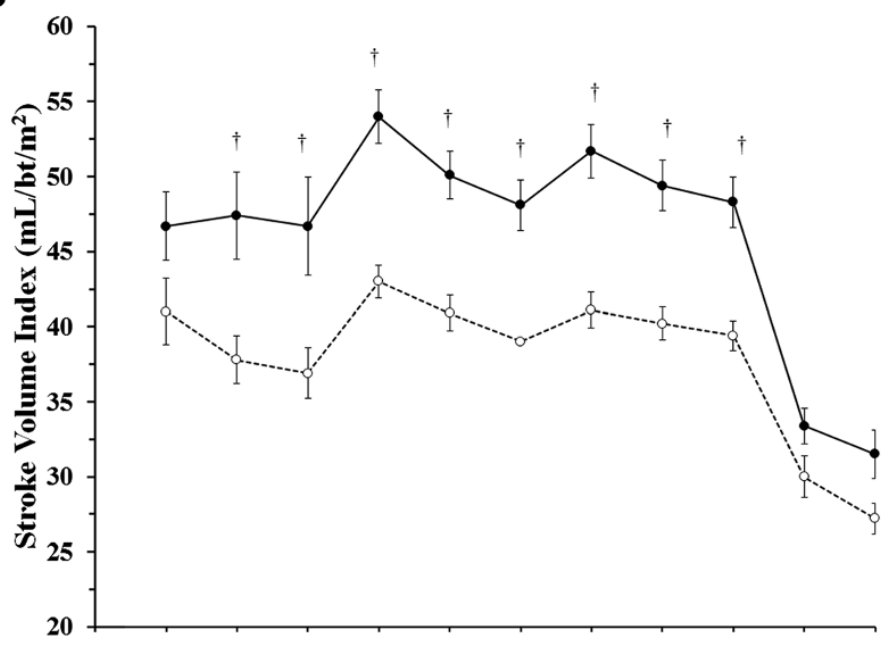

C

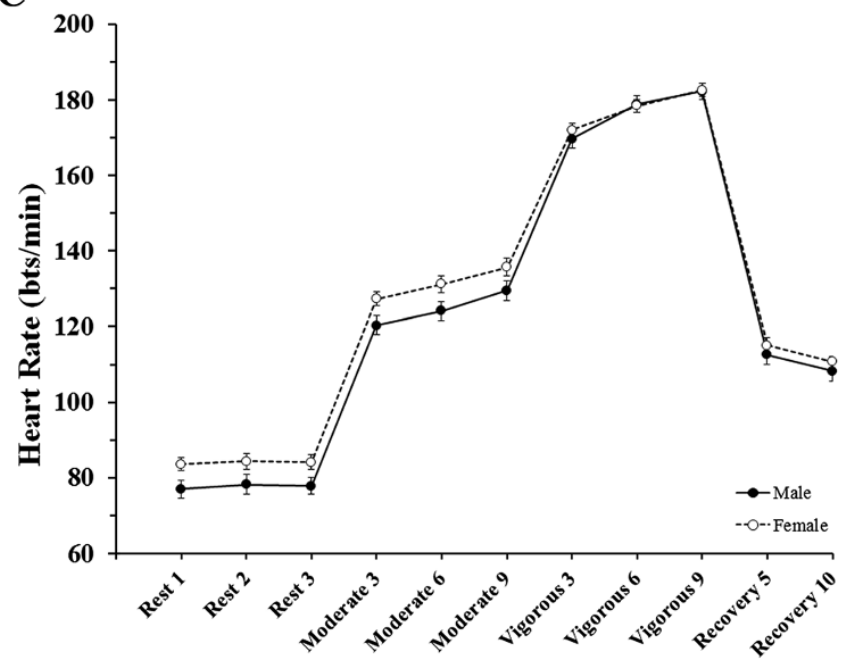

Figure 1 Sex differences in the cardiac response to constant-load submaximal exercise. Data are presented as mean \pm SEM at rest, moderate intensity constant-load exercise ( $40 \%$ peak workload), vigorous intensity constant-load exercise ( $70 \%$ peak workload), and at 5 and 10 minutes of recovery. These data demonstrate the differential cardiac response to constant-load exercise across sexes. Panel A: Cardiac Index; Panel B: Stroke Volume Index; Panel C: Heart Rate. Sex comparison: * $p<0.05, \dagger=p<0.01$. 
Figure 2 Sex differences in the systemic hemodynamic response to constant-load submaximal exercise. Data are presented as mean \pm SEM at rest, moderate intensity constant-load exercise ( $40 \%$ peak workload), vigorous intensity constant-load exercise ( $70 \%$ peak workload), and at 5 and 10 minutes of recovery. These data demonstrate the differential cardiac response to constant-load exercise across sexes. Panel A: Mean Arterial Pressure; Panel B: Systolic Blood Pressure; Panel C: Diastolic Blood Pressure; Panel D: Systemic Vascular Resistance. Sex comparison: ${ }^{*}=p<0.05,+=p<0.01$.

difference in DBP $(\mathrm{p}=0.51)$. In contrast to the lack of difference at the moderate intensity workload, the male participants demonstrated a lower $\mathrm{SVR}_{\mathrm{I}}$ compared to the female participants $(\mathrm{p}=0.04)$. Figures 1 and 2 show data for all 3 measurement time points during the vigorous intensity constant-load exercise for all cardiovascular measures. Blood lactate continued to accumulate until the end of exercise in both sexes, but tended to be lower in females (Figure 3).

\section{Sex differences in cardiovascular function during constant-load exercise correcting for differences in peak power}

Due to the apparent difference in aerobic fitness between sexes (i.e. the women's $\mathrm{VO}_{2 \mathrm{MAX}}$ was $80 \%$ that of the men's maximal aerobic capacity) and the likely differences in muscle mass, we corrected for differences in cardiovascular parameters dictated by maximal power output. Although the relative intensities were the same between sexes, 40 and $70 \%$ of maximal workload, we also compared responses as a function of the absolute power (wattage) performed by each subject (Table 5). When corrected for watts, absolute $\mathrm{VO}_{2}$ was not different between groups, demonstrating that the relative intensity, both moderate and vigorous, were similar between groups. During both moderate and vigorous intensity constant-load exercise, the female subjects appeared to be at a higher cardiopulmonary demand, as $\mathrm{VO}_{2}(\mathrm{ml} / \mathrm{kg} / \mathrm{min}), \mathrm{SV}, \mathrm{HR}, \mathrm{Q}$ and $\mathrm{AVO}_{2}$ difference corrected for watts were all higher when compared to their male counterparts $(\mathrm{p}<0.01$, for all). Work and energy expenditure were significantly higher in males at both moderate and vigorous workloads (Table 6). When correcting for differences in wattage, there was no difference at moderate intensity, but the energy expenditure per watt was lower in females at the vigorous intensity. There was no difference in mechanical efficiency at the moderate intensity (23\% for both) between sexes, but at the vigorous workload females were slightly more efficient ( 24 vs $23 \%$ females vs. males respectively), and the delta efficiency resulted in females being slightly more efficient with increasing intensity whereas there was no change in the males (Table 6). During both exercise intensities, the ventilatory equivalent for $\mathrm{O}_{2}$ and $\mathrm{CO}_{2}$ was higher in females when corrected for watts (Table 6). 
Table 3 Cardiovascular response to moderate intensity submaximal steady-state exercise

\begin{tabular}{|c|c|c|c|c|}
\hline & All & Male & Female & p-value \\
\hline \multicolumn{5}{|l|}{ Cardiovascular } \\
\hline $\mathrm{VO}_{2}(\mathrm{~mL} / \mathrm{min})$ & $1284.0 \pm 43.0$ & $1545.7 \pm 48.1$ & $1038.2 \pm 33.7$ & $<0.01$ \\
\hline $\mathrm{VCO}_{2}(\mathrm{~mL} / \mathrm{min})$ & $1161.7 \pm 39.4$ & $1403.3 \pm 43.4$ & $934.7 \pm 30.9$ & $<0.01$ \\
\hline $\mathrm{VO}_{2}(\mathrm{~mL} / \mathrm{kg} / \mathrm{min})$ & $17.7 \pm 3.0$ & $19.0 \pm 3.3$ & $16.5 \pm 2.0$ & $<0.01$ \\
\hline $\mathrm{Q}_{1}\left(\mathrm{~L} / \mathrm{min} / \mathrm{m}^{2}\right)$ & $5.8 \pm 0.8$ & $6.2 \pm 0.8$ & $5.4 \pm 0.6$ & $<0.01$ \\
\hline$S V_{1}\left(\mathrm{~mL} / \mathrm{m}^{2}\right)$ & $45.8 \pm 9.1$ & $50.4 \pm 9.2$ & $41.3 \pm 6.4$ & $<0.01$ \\
\hline $\mathrm{HR}(\mathrm{mL} / \mathrm{min})$ & $128.1 \pm 13.2$ & $124.6 \pm 13.7$ & $131.4 \pm 12.1$ & 0.04 \\
\hline $\mathrm{AVO}_{2}$ Difference ( $\mathrm{mL} \mathrm{O} / 100 \mathrm{~mL}$ blood) & $11.9 \pm 1.4$ & $12.6 \pm 1.2$ & $11.2 \pm 1.2$ & $<0.01$ \\
\hline $\mathrm{SBP}(\mathrm{mm} \mathrm{Hg})$ & $174.9 \pm 27.5$ & $188.8 \pm 23.5$ & $161.8 \pm 24.7$ & $<0.01$ \\
\hline $\mathrm{DBP}(\mathrm{mm} \mathrm{Hg})$ & $78.5 \pm 10.1$ & $82.2 \pm 10.2$ & $74.9 \pm 8.6$ & 0.01 \\
\hline MAP $(m m ~ H g)$ & $110.6 \pm 14.7$ & $117.7 \pm 13.2$ & $103.9 \pm 13.0$ & $<0.01$ \\
\hline $\mathrm{SVR}_{\mathrm{I}}\left(\mathrm{dyn} \mathrm{n}^{*} \mathrm{sec} / \mathrm{cm}^{5} / \mathrm{m}^{2}\right)$ & $1556.1 \pm 233.2$ & $1574.4 \pm 243.8$ & $1564.3 \pm 225.3$ & 0.72 \\
\hline Hemoglobin (gh/dL) & $15.4 \pm 1.4$ & $16.2 \pm 1.1$ & $14.0 \pm 0.7$ & $<0.01$ \\
\hline SOT $\left(\mathrm{mL} / \mathrm{min} / \mathrm{m}^{2}\right)$ & $1150.1 \pm 226.3$ & $1315.7 \pm 187.6$ & $994.5 \pm 127.7$ & $<0.01$ \\
\hline RPE & $10.4 \pm 1.3$ & $10.4 \pm 1.4$ & $10.4 \pm 1.1$ & 0.58 \\
\hline \multicolumn{5}{|l|}{ Blood gases } \\
\hline $\mathrm{PaO}_{2}(\mathrm{~mm} \mathrm{Hg})$ & $97.7 \pm 7.1$ & $97.2 \pm 6.0$ & $98.1 \pm 8.0$ & 0.56 \\
\hline $\mathrm{PaCO}_{2}(\mathrm{~mm} \mathrm{Hg})$ & $37.5 \pm 2.7$ & $38.4 \pm 2.6$ & $36.6 \pm 2.4$ & $<0.01$ \\
\hline $\mathrm{CaO}_{2}(\mathrm{~mL} / 100 \mathrm{~mL})$ & $19.9 \pm 1.8$ & $21.3 \pm 1.4$ & $18.5 \pm 0.9$ & $<0.01$ \\
\hline \multicolumn{5}{|l|}{ Catecholamines \& lactate } \\
\hline Epinephrine (pg/mL) & $100.8 \pm 37.9$ & $113.2 \pm 35.3$ & $89.1 \pm 37.1$ & 0.01 \\
\hline Norepinephrine $(\mathrm{pg} / \mathrm{mL})$ & $630.1 \pm 163.3$ & $693.2 \pm 172.4$ & $570.88 \pm 130.8$ & 0.02 \\
\hline Lactate (mM) & $3.00 \pm 1.269$ & $3.22 \pm 1.24$ & $2.78 \pm 1.32$ & 0.17 \\
\hline Lactate fold change from baseline & $3.3 \pm 2.0$ & $3.4 \pm 2.1$ & $3.1 \pm 1.9$ & 0.52 \\
\hline
\end{tabular}

See Table 2 for acronyms explained.

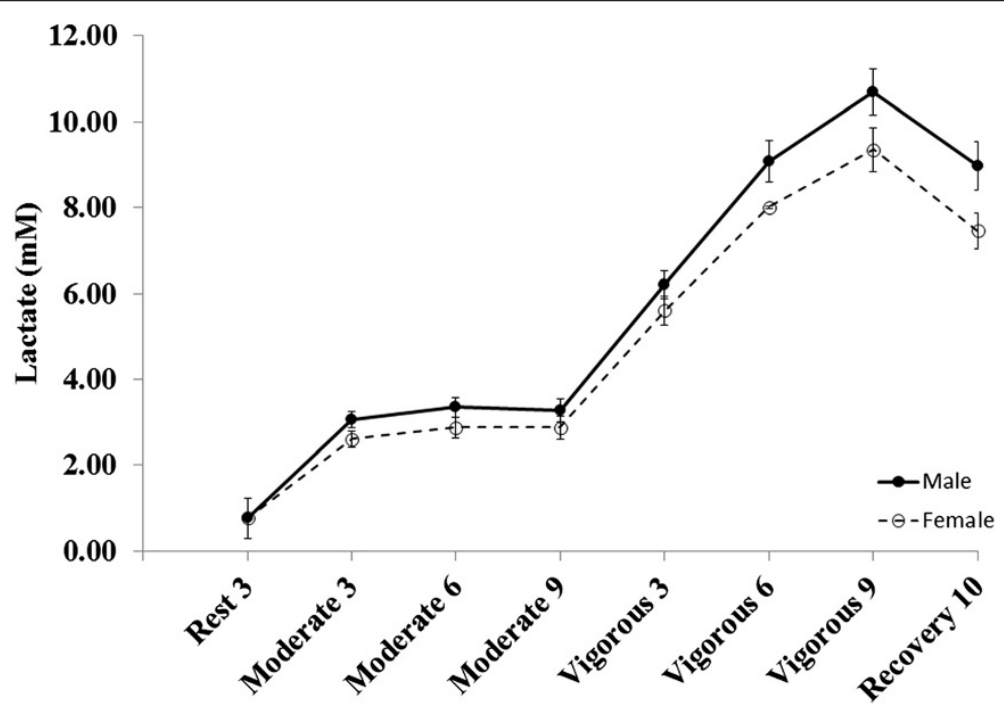

Figure 3 Lactate response to constant-load submaximal exercise. Data are presented as mean \pm SEM at the last minute of rest, moderate intensity constant-load exercise ( 40\% peak workload), vigorous intensity constant-load exercise ( $70 \%$ peak workload), and 10 minutes of recovery. 
Table 4 Cardiovascular response to vigorous intensity submaximal steady-state exercise

\begin{tabular}{|c|c|c|c|c|}
\hline & All & Male & Female & p-value \\
\hline \multicolumn{5}{|l|}{ Cardiovascular } \\
\hline $\mathrm{VO}_{2}(\mathrm{~mL} / \mathrm{min})$ & $2167.2 \pm 664.2$ & $2685.0 \pm 504.9$ & $1664.0 \pm 335.5$ & $<0.01$ \\
\hline $\mathrm{VCO}_{2}(\mathrm{~mL} / \mathrm{min})$ & $2257.7 \pm 744.5$ & $2801.8 \pm 603.7$ & $1746.4 \pm 440.7$ & $<0.01$ \\
\hline $\mathrm{VO}_{2}(\mathrm{~mL} / \mathrm{kg} / \mathrm{min})$ & $29.5 \pm 5.9$ & $32.9 \pm 5.7$ & $26.1 \pm 3.9$ & $<0.01$ \\
\hline $\mathrm{Q}_{1}\left(\mathrm{~L} / \mathrm{min} / \mathrm{m}^{2}\right)$ & $7.9 \pm 1.4$ & $8.7 \pm 1.4$ & $7.1 \pm 0.9$ & $<0.01$ \\
\hline $\mathrm{S} V_{1}\left(\mathrm{~mL} / \mathrm{m}^{2}\right)$ & $44.7 \pm 9.2$ & $49.6 \pm 9.5$ & $40.1 \pm 6.3$ & $<0.01$ \\
\hline $\mathrm{HR}$ (bts/min) & $177.2 \pm 11.0$ & $176.7 \pm 12.4$ & $177.7 \pm 9.9$ & 0.95 \\
\hline $\mathrm{AVO}_{2}$ Difference $(\mathrm{mL} \mathrm{O} / 100 \mathrm{~mL}$ blood) & $14.4 \pm 1.6$ & $15.3 \pm 1.3$ & $13.6 \pm 1.4$ & $<0.01$ \\
\hline $\mathrm{SBP}(\mathrm{mm} \mathrm{Hg})$ & $196.2 \pm 32.5$ & $212.9 \pm 26.3$ & $180.1 \pm 30.4$ & $<0.01$ \\
\hline $\mathrm{DBP}(\mathrm{mm} \mathrm{Hg})$ & $81.9 \pm 10.6$ & $83.5 \pm 11.6$ & $80.1 \pm 9.5$ & 0.29 \\
\hline MAP (mm Hg) & $120.0 \pm 15.8$ & $126.6 \pm 140$ & $113.4 \pm 14.9$ & $<0.01$ \\
\hline $\operatorname{SVR}\left(\right.$ dyn* $\left.\sec / \mathrm{cm}^{5} / \mathrm{m}^{2}\right)$ & $1237.8 \pm 192.9$ & $1190.4 \pm 200.0$ & $1279.4 \pm 180.9$ & 0.047 \\
\hline Hemoglobin (g/dL) & $15.5 \pm 1.5$ & $16.7 \pm 1.1$ & $14.4 \pm 0.7$ & $<001$ \\
\hline SOT $\left(\mathrm{mL} / \mathrm{min} / \mathrm{m}^{2}\right)$ & $1619.9 \pm 371.1$ & $1889.5 \pm 303.5$ & $1366.6 \pm 219.4$ & $<0.01$ \\
\hline RPE & $16.4 \pm 0.9$ & $16.4 \pm 0.9$ & $16.3 \pm 0.9$ & 0.75 \\
\hline \multicolumn{5}{|l|}{ Blood gases } \\
\hline $\mathrm{PaO}_{2}(\mathrm{~mm} \mathrm{Hg})$ & $98.6 \pm 7.4$ & $97.6 \pm 6.9$ & $99.4 \pm 7.7$ & 0.17 \\
\hline $\mathrm{PaCO}_{2}(\mathrm{~mm} \mathrm{Hg})$ & $32.9 \pm 2.9$ & $33.6 \pm 2.8$ & $32.4 \pm 2.9$ & 0.18 \\
\hline $\mathrm{CaO}_{2}(\mathrm{~mL} / 100 \mathrm{~mL})$ & $20.4 \pm 1.9$ & $21.9 \pm 1.5$ & $19.1 \pm 0.9$ & $<0.01$ \\
\hline \multicolumn{5}{|l|}{ Catecholamines \& lactate } \\
\hline Epinephrine (pg/mL) & $318.0 \pm 231.3$ & $389.7 \pm 286.2$ & $250.7 \pm 137.7$ & 0.01 \\
\hline Norepinephrine (pg/mL) & $2252.8 \pm 859.5$ & $2508 . \pm 946.3$ & $2012.5 \pm 701.5$ & 0.02 \\
\hline Lactate (mM) & $8.16 \pm 2.46$ & $8.79 \pm 2.39$ & $7.68 \pm 2.39$ & 0.08 \\
\hline Lactate fold change from baseline & $11.1 \pm 5.1$ & $11.5 \pm 5.9$ & $10.9 \pm 4.3$ & 0.61 \\
\hline
\end{tabular}

See Table 2 for acronyms explained.

Table 5 Cardiovascular function during constant-load exercise correcting for differences in peak power

\begin{tabular}{|c|c|c|c|c|}
\hline & All & Male & Female & p-value \\
\hline \multicolumn{5}{|l|}{ Moderate } \\
\hline $\mathrm{VO}_{2}(\mathrm{~mL} / \mathrm{min}) / \mathrm{Watt}$ & $16.24 \pm 2.00$ & $15.96 \pm 2.01$ & $16.5 \pm 1.99$ & 0.26 \\
\hline $\mathrm{VO}_{2}(\mathrm{~mL} / \mathrm{kg} / \mathrm{min}) / \mathrm{Watt}$ & $0.23 \pm 0.05$ & $0.20 \pm 0.03$ & $0.26 \pm 0.05$ & $<0.01$ \\
\hline $\mathrm{Q}(\mathrm{L} / \mathrm{min}) / \mathrm{Watt}$ & $0.14 \pm 0.02$ & $0.13 \pm 0.02$ & $0.15 \pm 0.03$ & $<0.01$ \\
\hline SV $(\mathrm{mL}) /$ Watt & $1.0 \pm 0.18$ & $1.05 \pm 0.13$ & $1.14 \pm 0.21$ & $<0.01$ \\
\hline HR (bts/min)/Watt & $1.77 \pm 0.65$ & $1.34 \pm 0.38$ & $2.18 \pm 0.58$ & $<0.01$ \\
\hline $\mathrm{AVO}_{2}$ Difference $(\mathrm{mL} \mathrm{O} / 100 \mathrm{~mL}$ blood)/Watt & $0.19 \pm 0.23$ & $0.19 \pm 0.34$ & $0.18 \pm 0.04$ & $<0.01$ \\
\hline \multicolumn{5}{|l|}{ Vigorous } \\
\hline $\mathrm{VO}_{2}(\mathrm{~mL} / \mathrm{min}) / \mathrm{Watt}$ & $13.75 \pm 0.94$ & $13.85 \pm 0.84$ & $13.65 \pm 1.03$ & 0.4 \\
\hline $\mathrm{VO}_{2}(\mathrm{~mL} / \mathrm{kg} / \mathrm{min}) / \mathrm{Watt}$ & $0.20 \pm 0.04$ & $0.17 \pm 0.02$ & $0.22 \pm 0.04$ & $<0.01$ \\
\hline $\mathrm{Q}(\mathrm{L} / \mathrm{min}) / \mathrm{Watt}$ & $0.10 \pm 0.01$ & $0.09 \pm 0.01$ & $0.10 \pm 0.01$ & $<0.01$ \\
\hline SV $(\mathrm{mL}) /$ Watt & $0.55 \pm 0.08$ & $0.52 \pm 0.06$ & $0.57 \pm 0.09$ & $<0.01$ \\
\hline $\mathrm{HR}$ (bts/min)/Watt & $1.24 \pm 0.40$ & $0.95 \pm 0.25$ & $1.50 \pm 0.38$ & $<0.01$ \\
\hline $\mathrm{AVO}_{2}$ Difference $(\mathrm{mL} \mathrm{O} / 100 \mathrm{~mL}$ blood)/Watt & $0.10 \pm 0.03$ & $0.08 \pm 0.02$ & $0.11 \pm 0.02$ & $<0.01$ \\
\hline
\end{tabular}


Table 6 Work, energy expenditure and mechanical efficiency during moderate and vigorous constant-load exercise

\begin{tabular}{|c|c|c|c|c|}
\hline & All & Male & Female & p-value \\
\hline Resting energy expenditure (kcal/min) & $1.31 \pm 0.36$ & $1.52 \pm 0.36$ & $1.01 \pm 0.24$ & $<0.01$ \\
\hline \multicolumn{5}{|l|}{ Moderate } \\
\hline Work (kcal/min) & $1.15 \pm 0.36$ & $1.41 \pm 0.29$ & $0.92 \pm 0.22$ & $<0.01$ \\
\hline Energy expenditure (kcal/min) & $5.01 \pm 1.50$ & $6.13 \pm 1.14$ & $3.96 \pm 0.91$ & $<0.01$ \\
\hline Energy expenditure/Watts (kcal/min)/Watt & $0.62 \pm 0.006$ & $0.063 \pm 0.009$ & $0.63 \pm 0.01$ & 0.52 \\
\hline $\mathrm{V}_{\mathrm{E}} \mathrm{NO} 2$ & $27.5 \pm 3.4$ & $26.1 \pm 2.7$ & $28.9 \pm 3.4$ & $<0.01$ \\
\hline $\mathrm{V}_{\mathrm{E}} \mathrm{NO}_{2} /$ Watt & $0.38 \pm 0.15$ & $0.28 \pm 0.08$ & $0.48 \pm 0.13$ & $<0.01$ \\
\hline $\mathrm{V}_{\mathrm{E}} \mathrm{NCO} 2$ & $30.5 \pm 2.8$ & $29.0 \pm 1.9$ & $32.0 \pm 2.8$ & $<0.01$ \\
\hline Mechanical efficiency (\%) & $23.2 \pm 3.7$ & $23.1 \pm 3.8$ & $23.4 \pm 3.6$ & 0.59 \\
\hline \multicolumn{5}{|l|}{ Vigorous } \\
\hline Work (kcal/min) & $2.29 \pm 0.73$ & $2.81 \pm 0.60$ & $1.80 \pm 0.46$ & $<0.01$ \\
\hline Energy expenditure (kcal/min) & $9.59 \pm 3.19$ & $11.98 \pm 2.45$ & $7.37 \pm 1.96$ & $<0.01$ \\
\hline Energy expenditure/Watts (kcal/min)/Watt & $0.006 \pm 0.007$ & $0.061 \pm 0.006$ & $0.059 \pm 0.007$ & $<0.01$ \\
\hline $\mathrm{V}_{\mathrm{E}} \mathrm{NO2}$ & $34.4 \pm 4.9$ & $33.4 \pm 5.0$ & $35.3 \pm 4.6$ & $<0.01$ \\
\hline $\mathrm{V}_{\mathrm{E}} \mathrm{NO}_{2} /$ Watt & $0.24 \pm 0.09$ & $0.18 \pm 0.06$ & $0.30 \pm 0.08$ & $<0.01$ \\
\hline $\mathrm{V}_{\mathrm{E}} \mathrm{NCO} 2$ & $32.8 \pm 4.2$ & $31.5 \pm 4.0$ & $34.0 \pm 4.0$ & $<0.01$ \\
\hline Mechanical efficiency (\%) & $24.1 \pm 2.6$ & $23.5 \pm 2.3$ & $24.6 \pm 2.7$ & $<0.01$ \\
\hline Delta efficiency (vigorous-moderate) & $0.82 \pm 2.12$ & $0.37 \pm 2.25$ & $1.24 \pm 1.69$ & 0.10 \\
\hline
\end{tabular}

\section{Discussion}

This study examined the influence of sex on the cardiovascular response to submaximal steady-state exercise in healthy humans. The results of this study suggest that during steady-state exercise at matched relative workloads of both moderate ( $40 \%$ peak workload) and vigorous $(75 \%$ peak workload) submaximal intensity the female participants demonstrated lower Q mediated by reduced SV compared to males even when indexed for BSA. In addition, the female participants demonstrated lower SBP (with non-significantly lower DBP) resulting in reduced MAP. Despite these differences, the SVR remained similar at rest and moderate intensity and only became different during vigorous intensity exercise between the male and female participants suggesting that the regulation and homeostatic relationship between blood pressure and cardiac output is achieved through different mechanisms in males and females. This research advances our current understanding of the differences in cardiovascular hemodynamics during exercise between sexes for a number of reasons including the recruitment of a robust sample size, placement of an intra-arterial and a venous catheter for measures of arterial blood pressure and simultaneous assessment of plasma catecholamines and blood gases. Further, we have analyzed our data to extensively consider differences in body size and work capacity which will affect cardiovascular responses independent other sexmediated differences.

When comparing the $\mathrm{Q}_{\mathrm{I}}$ and $\mathrm{SV}_{\mathrm{I}}$ across sexes to account for differences in body size, our results suggest that both the male and female participants had a similar HR, with a trend for higher HRs in females, at both submaximal exercise intensities, consistent with prior studies evaluating across relative workloads during a maximal exercise test (Ogawa et al. 1992; Fleg et al. 1995). Despite this similarity, $\mathrm{Q}_{\mathrm{I}}$ was lower at both exercise intensities in female participants as a result of reduced $\mathrm{SV}_{\mathrm{I}}$. This would suggest that since $\mathrm{Q}_{\mathrm{I}}$ was lower and $\mathrm{HR}$ was similar between the groups, the female participants had a greater reliance on HR to increase $\mathrm{Q}_{\mathrm{I}}$ compared to the male participants. This follows the conclusions by Ogawa et al. that differences in stroke volume are the primary cause of sex differences in cardiac output during maximal and now submaximal exercise (Ogawa et al. 1992). Our work extends upon the previous work by both Fleg et al. and Sullivan et al. which examined the sex-based differences in cardiac volumes and cardiac index in subjects $<40$ years old group during peak upright cycle exercise (Fleg et al. 1995; Sullivan et al. 1991). In contrast to our findings, neither of these previous studies noted any differences in $\mathrm{Q}_{\mathrm{I}}$ and $\mathrm{SV}_{\mathrm{I}}$ between sexes at relative submaximal exercise. Although all groups were of the same age, there were clear differences in fitness level as these other populations were sedentary, excluding anyone who exercise $>3$ times/week. The fitness/ activity level difference between their populations and ours is clear when reviewing the lower peak work rates in both sexes when compared to our population (men: 149/ 157 vs. 252 W; females: $102 / 115$ vs. $190 \mathrm{~W}$, subject populations: Fleg/Sullivan vs Wheatley respectively). We believe the ability of our subjects to reach higher workloads 
and create a greater cardiac demand, allowed us to see differences that were not apparent in the sedentary individuals of the previous work. Additionally, the methodology used to assess cardiac function differed between the current and previous studies, in that the previous studies utilized gated radionuclide angiography for assessment of cardiac volumes: end diastolic and systolic volumes, ejection fraction, and direct Fick for Q and SV, whereas we measured Q from the acetylene open circuit method. The open circuit acetylene method for measurement of $\mathrm{Q}$ has been validated against direct Fick and shown to have a strong correlation particularly during exercise. In some instances, Q measured via acetylene open circuit may underestimate actual $Q$ at higher workloads suggesting that the differences we present in the current study may have been larger if calculated from direct Fick (Johnson et al. 2000a).

Despite exercising subjects at the same percentage of peak watts to keep subjects at similar relative exercise intensity, $\mathrm{VO}_{2}$ remained different between sexes at both submaximal intensities. Because $\mathrm{VO}_{2}$ and $\mathrm{Q}$ follow wattage, we also made comparisons after correcting for differences in wattage to determine if this was driving the differences observed. We found that the differences remained between males and females except that they were in the opposite direction, such that for a given wattage females were demanding more, having a greater $\mathrm{Q}$ and its components, $\mathrm{SV}$ and HR, for a given wattage when compared to male participants. This elevated Q, HR, and SV highlights a greater cardiac work needed to meet the same physical work demands. In an attempt to compensate for the specific reduced cardiac performance, these women increased peripheral oxygen extraction as evidenced by the higher $\mathrm{AVO}_{2}$ difference when corrected for wattage. Analysis of mechanical work, energy expenditure, and efficiency also suggest the tendency to be more efficient with their resources especially during vigorous exercise which allowed females to accommodate the increase in cardiopulmonary demand. Additionally, lactate accumulation tended to be lower in females at the end of vigorous exercise following the rightward displacement of lactate accumulation in response to maximal exercise in women which has been demonstrated previously and suggested to provide a potential offset for their lower $\mathrm{VO}_{2}$ and greater cardiac demand by allowing for increased capacity to accomplish the work (Sargent and Scroop 2007).

This study extends upon previous investigation conducted during maximal exercise and demonstrates that during submaximal constant-load exercise intensities men have a greater reliance on the Frank-Starling mechanism to meet the increased cardiac demand and that the differences in cardiac output are driven by limitations in stroke volume in females. Previous research suggests a reason for this apparent blunted increase in stroke volume may be differences autonomic regulation in that females have reduced sympathetic and $\alpha$-adrenergic responsiveness and a greater reliance on $\beta$-receptor mediated vasodilatation and increased parasympathetic tone (Kneale et al. 1997; Kneale et al. 2000; Schmitt et al. 2010; Evans et al. 2001). Further, although measurements were taken at rest, muscle sympathetic nerve activity (MSNA), a measure of sympathetic system activity, has been shown to be lower in females (Charkoudian et al. 2005). Additionally, the lower incidence of cardiovascular disease in premenopause women and marked increase in the incidence of hypertension around the age of menopause has been attributed to changes in female reproductive hormones where estrogen has been shown to reduce NE-induced vasoconstriction, can promote endothelium-dependent vasodilation through increasing the bioavailability of $\mathrm{NO}$, and increase $\beta_{2}$-receptor sensitivity (Charkoudian 2001; Kneale et al. 1997; Hart et al. 2011; Sudhir et al. 1997). Both Fleg et al. and our current study demonstrate lower $\mathrm{NE}$ in females at rest and during exercise, which could limit $\beta_{1}$-receptor activation and thereby reduce cardiac contractility. Therefore, these data suggest that females demonstrate reduced or limited SV and subsequently Q possibly due blunted sympathetic nervous system activity along with an elevated basal vasodilatory state limiting/ blunting the increase in vascular tone to augment venous return and sympathetic activity to increase cardiac contractility during exercise. To this regard, it appears that the females in this study attempted to compensate for this through increasing HR (via increased parasympathetic withdrawal) and oxygen extraction. This increase in extraction is in line with previous work where arterial $\mathrm{O}_{2}$ content has been shown to be reduced in females solely due to differences in $\mathrm{Hb}$ as arterial $\mathrm{O}_{2}$ was similar, but mixed venous $\mathrm{O}_{2}$ was lower at rest and during submaximal exercise when compared to men (Sullivan et al. 1991).

A critical component of the cardiovascular response to exercise is an increase in blood pressure to maintain perfusion pressure to the heart, brain, and other vital organs (Rowell 1993). Changes in blood pressure are a function of the change in cardiac output and the peripheral resistance to forward flow typically mediated by vascular tone. Despite a significant increase in sympathetically mediated vasoconstriction, typically peripheral resistance will fall during exercise due greater metabolically mediated vasodilation of the active muscles (Joyner 2006; Joyner et al. 2008). However, in most cases, blood pressure will increase since the increase in cardiac output is more than adequate to compensate for the reduction in peripheral resistance.

It is known that in young healthy men, total peripheral resistance is positively related to MSNA, suggesting that a primary mediator of vascular tone is sympathetic nervous system outflow (Narkiewicz et al. 2005). Interestingly, it has been shown that in young healthy women, resting blood pressure is typically lower than that observed in 
men of the same age (Burt et al. 1995). Moreover, the incidence of orthostatic hypotension is greater in women than in men (Fu et al. 2005), and women have lower tonic autonomic support of resting arterial pressure (Christou et al. 2005). These observations would suggest that the contribution of sympathetically mediated vasoconstrictor tone to arterial pressure regulation differs in men and women. In fact, it has recently been demonstrated that typically the interrelationships between SVR, Q, and sympathetic neural control of vascular tone do not exist in young women under resting conditions (Hart et al. 2009). Specifically, Hart and colleagues suggest that in young healthy women, sympathetic nerve activity does not determine SVR and further Q is not balanced with sympathetic activity to maintain normal arterial pressure as is typically seen in young healthy men (Hart et al. 2009).

Our results demonstrate that the female participants had a lower resting blood pressure compared to the male participants. Moreover, at both levels of submaximal exercise the female participants demonstrated significantly lower systolic blood pressure which contributed to lower MAP. However, these differences coupled with the differences in cardiac output resulted in a similar SVR response to the exercise session, following what has been demonstrated in relative stages of peak exercise testing previously (Fleg et al. 1995; Ogawa et al. 1992). This suggests that although blood pressure was ultimately lower in the female participants, the SVR response was the same between the male and female participants.

\section{Limitations}

In this study percentage of peak work rate was used to match relative intensities between sexes, however, recent work has suggested this methodology is not ideal due to differences in gas exchange threshold and critical power between individuals (Katch et al. 1978; Lansley et al. 2011). As such the moderate and vigorous intensities compared in this study may under/overestimate work rates or physiological demand for all individuals, which could shift individuals to different points on the $\mathrm{VO}_{2}$ kinetic continuum and thereby alter the cardiopulmonary demand. Although using \% work rate to match exercise intensities may increase the variability of the responses, our lactate measurements taken every three minutes during these submaximal workloads suggests that the intensities were quite similar for the majority of the individuals and between sexes. The blood lactate levels increased and plateaued during the moderate intensity work, and increased at each measurement through the nine minutes the vigorous intensity work as would be expected for both sexes. However, continued research in this area is needed to validate our findings, particularly at submaximal intensities. One alternative approach to standardizing cardiac demand may be to use the percent delta concept as described by Lansley et al.
(Lansley et al. 2011). Additionally, females in this study were not all tested in the early follicular phase of their menstrual cycle which could have added additional variability to the response observed in these women; however controlling for this phase would likely have made the differences noted in this study more robust. Additional insight may be gleaned with future research examining females in both their early follicular phase and during their luteal phase.

\section{Conclusion}

The results of this study suggest a differential regulation of cardiovascular function between sexes during constantload submaximal exercise, corroborating with previous findings of differences in cardiovascular function at rest and maximal exercise. Correcting for differences in size, females demonstrate a lower SV, which they are unable to compensate for through increases in $H R$ as $\mathrm{Q}_{\mathrm{I}}$ and $\mathrm{SV}_{\mathrm{I}}$ are both lower in females. When corrected for wattage, females demonstrate elevated Q, HR, and SV with increased peripheral oxygen extraction as a compensatory mechanism (indicated by higher $\mathrm{VO}_{2}$ and $\mathrm{AVO}_{2}$ difference and improvements in mechanical efficiency) when compared to males highlighting greater cardiac work needed to meet the same physical work demand. The limitations in stroke volume could be the result of a female's blunted sympathetic response and higher basal vasodilatory state, evidenced by lower catecholamine levels in women at rest and through submaximal exercise. Moreover both sexes had similar SVR while SBP and MAP were higher in men suggesting that the relationship between $Q$ and MAP remained similar across sexes. These data are in agreement with previous findings suggesting sex differences in the regulation of arterial tone and extend these findings to suggest that the outcome of the difference in regulation is similar (i.e. no difference in SVR).

\section{Methods}

\section{Participant characteristics}

Sixty-four healthy adults (men: 21-40 years; women: 20-40 years), non-sedentary (exercising $>3$ times/week) were recruited to participant in this study. All participants were recruited from the surrounding community and were healthy, non-smokers with no evidence of cardiovascular, pulmonary, or musculoskeletal disease and were not pregnant or currently taking any medications (except for birth control). The protocol was approved by the Mayo Clinic Institutional Review Board and all participants gave written informed consent prior to participation. All aspects of the study conformed to the Declaration of Helsinki and Health Insurance Portability and Accountability Act (HIPAA) guidelines. 


\section{Overview of protocol}

Parts of the data generated by this study have been published elsewhere, where the objective was to explore the cardiovascular consequences of exercise according to beta2 adrenergic receptor genotype (Snyder et al. 2006) and to examine the difference between manual cuff auscultation vs. intra-arterial blood pressure measurement techniques (Wheatley et al. 2013). In these studies, data was grouped according to beta- 2 adrenergic receptor genotypes or as a whole comparing agreement between the blood pressure measurement techniques within an individual. The cardiovascular parameters in these previous manuscripts were presented under different stratification and with a different focus, but never evaluating differences in cardiovascular response between sexes as presented in this manuscript.

During visit one, participants reported to the Mayo Clinic - Clinical Research Unit to provide a blood sample to rule out anemia and pregnancy in women. All of the participants underwent baseline pulmonary function testing according to ATS standards (ATS 1995) (Elite Series Plethysmography, Medical Graphics, St. Paul, MN) and an incremental exercise test on an electromagnetically braked upright cycle ergometer to maximal volition (Corival, Lode Medical Technology, Netherlands). The incremental exercise test progressed in a manor appropriate for the subject's body size and his/her reported type, speed, and intensity of exercise training to provide a test duration of 10-16 minutes or five to eight stages (test duration: males 14:00 $\pm 2: 47$; females 13:07 $\pm 2: 21, \mathrm{p}=0.10$ ). Subjects exercised at an initial workload ranging between 20-50 watts (mean initial workload: males $36 \pm 8 \mathrm{~W}$; females $25 \pm 7 \mathrm{~W}$ ) with the workload increasing by this initial workload (wattage) every two minutes until exhaustion.

On visit two, participants were instrumented with a $5 \mathrm{~cm}$ 20-gauge Teflon coated indwelling catheter (FA-04020, Arrow International Inc., Reading, PA) placed in the radial artery after local anesthesia with $2 \%$ lidocaine. This catheter was used for the direct measurement of arterial blood pressure (BP). Resting measurements of $\mathrm{Q}$, heart rate (HR), and $\mathrm{BP}$ were made and stroke volume (SV) was calculated. The participants then exercised for nine minutes at 40\% (moderate intensity) and nine minutes at $~ 75 \%$ (vigorous intensity) of their peak workload achieved during the initial exercise studies while measurements were repeated every 2-3 minutes. Nine-minutes of exercise at each workload was performed because pilot data in our laboratory suggested that this was an adequate time frame to obtain three sets of measurements, and bringing the participants close to exhaustion during the higher workload.

For both study visits, prior to exercise testing participants were fitted with a nose clip and a mouthpiece attached to a PreVent Pneumotach (Medical Graphic, St. Paul, MN). For maximal exercise testing, all participants were verbally encouraged to continue the exercise protocol to maximal volition, determined by an inability to maintain a cadence between 60 to $80 \mathrm{rpm}$, a respiratory exchange ratio greater than 1.10 and/or a rating of perceived exertion (RPE) $\geq 17$ (Borg scale $=6-20)$ (Borg 1982). This baseline exercise study served as a screening tool and was used to determine work intensities for study visit two.

\section{Data collection \\ Measurement of ventilation and gas exchange}

Oxygen consumption $\left(\mathrm{VO}_{2}\right)$, carbon dioxide production $\left(\mathrm{VCO}_{2}\right)$, minute ventilation, respiratory rate and tidal volume were measured continuously during all exercise testing using a metabolic measurement system (MedGraphics CPX/D; Medical Graphics, St. Paul, MN) interfaced with a mass spectrometer (MGA 1100, Marquette Electronics, Milwaukee, WI). Manual volume calibration was performed with a three liter syringe and gas calibration was performed using manufacturer-recommended gases of known concentration. All calibration procedures were conducted immediately prior to each testing protocol. This system has been validated against classic "Douglas bag" collection techniques, and the stability of measurements verified by regular testing at standard exercise intensities by laboratory personnel (Proctor and Beck 1996).

\section{Assessment of cardiovascular function}

Cardiac output was measured using a 8-10 breath opencircuit acetylene wash-in technique as described previously (Johnson et al. 2000b). Briefly, the pneumotachograph was connected to a non-rebreathing $\mathrm{Y}$ valve (Hans Rudolph, $\mathrm{KC}, \mathrm{MO})$ with the inspiratory port connected to a pneumatic switching valve (Hans Rudolph, KC, MO) which allowed for rapid switching from room air to the test gas mixture (a large reservoir containing $0.7 \% \mathrm{C}_{2} \mathrm{H}_{2}, 21 \% 0_{2}, 9 \%$ $\mathrm{He}$, Balance $\mathrm{N}_{2}$ ). Gases were sampled using the mass spectrometer which was integrated with custom analysis software for the assessment of Q using our previously described iterative technique which has been validated against the direct Fick method (Johnson et al. 2000b). Heart rate was measured continuously by standard 12lead electrocardiogram (GE Case, GE Medical Systems, Milwaukee, WI). Stroke volume was calculated by dividing the Q by the HR. Both Q and SV were standardized to body surface area (BSA) to obtain the Q and SV indexes $\left(\mathrm{Q}_{\mathrm{I}}\right.$ and $\mathrm{SV}_{\mathrm{I}}$, respectively).

Intra-arterial BP was measured using a SpaceLab 512D patient monitor (SpaceLabs Inc., Hillsboro, OR). Mean arterial pressure (MAP) was calculated using the equation: $\mathrm{MAP}=\mathrm{DBP}+1 / 3(\mathrm{SBP}-\mathrm{DBP})$, where $\mathrm{DBP}$ is diastolic blood pressure and SBP is systolic blood pressure. Systemic vascular resistance (SVR) was calculated as the mean arterial pressure divided by $\mathrm{Q}$ and multiplied by 80 (conversion from Woods units). Systemic vascular resistance was then divided by BSA to obtain 
the systemic vascular resistance index $\left(\mathrm{SVR}_{\mathrm{I}}\right)$. The intra-arterial catheter also provided access for collection of arterial blood for the measurement of arterial catecholamines (see below for catecholamines), arterial blood gases, lactate, and hemoglobin content (partial pressure of arterial oxygen $\left(\mathrm{PaO}_{2}\right)$ and oxygen saturation $\left(\mathrm{SaO}_{2}\right)$. Arterial oxygen content $\left(\mathrm{CaO}_{2}\right)$ was calculated using the following equation:

$$
\mathrm{CaO}_{2}=\left(1.34 * \mathrm{Hgb} * \mathrm{SaO}_{2}\right)+\left(\mathrm{PaO}_{2} * 0.0031\right)
$$

Systemic oxygen transport (SOT) was calculated as $\mathrm{CaO}_{2}$ multiplied by Q.

Arterial-venous oxygen $\left(\mathrm{AVO}_{2}\right)$ difference was calculated according to the Fick equation:

$$
\mathrm{AVO}_{2} \text { Difference }=\left(\mathrm{Q} / \mathrm{VO}_{2}\right) / 10
$$

\section{Calculation of work, energy expenditure and mechanical efficiency}

Work was converted from watts to $\mathrm{kcal} / \mathrm{min}$ by multiplying watts by 0.01433 . Energy expenditure (EE) was calculated by subtracting resting $\mathrm{VO}_{2}(\mathrm{~mL} / \mathrm{min})$ from the exercising $\mathrm{VO}_{2}$ and multiplying by the RER caloric equivalent taken from the table published by Foss and Keteyian (Foss and Keteyian 1988; p 83). Mechanical efficiency was then determined by dividing work by energy expenditure and expressing as a percentage.

\section{Measurement of catecholamines and lactate}

Epinephrine (EPI), norepinephrine (NE) and lactate were measured according to methods developed in the Mayo Clinic Clinical Research Unit immunochemical core laboratory and the methods of Sealey (Sealey 1991). For EPI, our laboratory intra-assay coefficients of variation (CVs) are $12.2 \%$ and $3.6 \%$ at 13.8 and $242 \mathrm{pg} / \mathrm{mL}$. Interassay CVs are $8.5 \%$ and $6.3 \%$ at 179 and $390 \mathrm{pg} / \mathrm{mL}$. Plasma lactate was measured using Roche Cobas c311 chemistry analyzer using an enzymatic reaction to convert lactate to pyruvate (Roche Diagnostics Corp. Indianapolis, IN 46250). Intra-assay CVs are $8.9 \%$ and $1.6 \%$ at 0.8 and $4.9 \mathrm{mmol} / \mathrm{L}$ respectively. Inter-assay $\mathrm{CVs}$ are $4.9 \%$, and $1.2 \%$ at 1.2 and $4.6 \mathrm{mmol} / \mathrm{L}$ respectively.

\section{Statistical analysis}

Statistical analysis and graphic presentation were accomplished using SPSS (v 12.0, Chicago, IL) and GraphPad Prizm (v 4.0, San Diego, CA). The demographic data was examined using two-tailed unpaired Students T-tests. Analysis of variance (ANOVA) with Tukey HSD was conducted to determine differences at rest and during exercise for Q, HR, SV, SBP, DBP, MAP and SVR between groups. All data were found to have homogeneity of variance prior to the ANOVA using
Levene's test for equality of variance. Statistical significance was set at an alpha level of 0.05 for all analyses. Data are presented as mean \pm standard deviation unless otherwise indicated.

\section{Abbreviations}

$\mathrm{AVO}_{2}$ : Arterial to venous $\mathrm{O} 2$ difference; BMI: Body mass index; BSA: Body surface area; $\mathrm{CaO}_{2}$ : Arterial oxygen content; DBP: Diastolic blood pressure; EPI: Epinephrine; HR: Heart rate; MAP: Mean arterial blood pressure; $\mathrm{NE}$ : Norepinephrine; $\mathrm{PaCO}_{2}$ : Arterial partial pressure of carbon dioxide; $\mathrm{PaO}_{2}$ : Arterial partial pressure of oxygen; Q: Cardiac output; $\mathrm{Q}_{1}$ : Cardiac index; RPE: Rating of perceived exertion; $\mathrm{SaO}_{2}$ : Oxygen saturation; SBP: Systolic blood pressure; SOT: Systemic oxygen transport; SV: Stroke volume; $\mathrm{SV}_{\text {: }}$ : Stroke volume index; SVR: Systemic vascular resistance; SVR; : Systemic vascular resistance index; $\mathrm{VCO}_{2}$ : Carbon dioxide production; $\mathrm{VO}_{2}$ : Oxygen consumption.

\section{Competing interests}

CMW, EMS, BDJ, and TPO declare they have no conflict of interests.

\section{Authors' contributions}

EMS, BDJ, and TPO were responsible for study design and data collection. CMW, EMS, BDJ and TPO were responsible for analysis and manuscript writing. All authors read and approved the final manuscript.

\section{Acknowledgements}

We would like to thank Kathy O'Malley, Chris Johnson, and Shelly Roberts for their assistance with data collection. We also thank the participants for their effort. This work was supported by grant numbers HL71478 (BDJ) and 1KL2RR024151 (TPO) from the National Institutes of Health (NIH) and grant number 560512 (EMS) from the American Heart Association. We also thank the staff of the Clinical Research Unit (CRU) for their assistance throughout this study. The Mayo Clinic CRU is supported by grant number

1UL1RR024150 from the National Center for Research Resources (NCRR).

\section{Author details}

${ }^{1}$ Division of Cardiovascular Diseases, Mayo Clinic, 200 1st Street, SW, Rochester, MN 55905, USA. ${ }^{2}$ Department of Kinesiology, University of Minnesota, Minneapolis, MN, USA.

Received: 31 July 2014 Accepted: 9 August 2014

Published: 20 August 2014

\section{References}

Adams KF, Vincent LM, McAllister SM, el-Ashmawy H, Sheps DS (1987) The influence of age and gender on left ventricular response to supine exercise in asymptomatic normal subjects. Am Heart J 113(3):732-742

ATS (1995) Standardization of spirometry: 1994 Update. American Thoracic Society. Am J Respir Crit Care Med 152:1107-1136

Borg GAV (1982) A Category Scale With Ratio Properties for Intermodal and Interindividual Comparisons. In: Geissler H, Pezold P (eds) Psychophysial Judgement and the Process of Perception. Veb Deutsche Verlag Wissen Schaften, Berlin, pp 25-34

Burt VL, Whelton P, Roccella EJ, Brown C, Cutler JA, Higgins M, Horan MJ, Labarthe D (1995) Prevalence of hypertension in the US adult population. Results from the Third National Health and Nutrition Examination Survey: 1988-1991. Hypertension 25:305-313

Charkoudian N (2001) Influences of female reproductive hormones on sympathetic control of the circulation in humans. Clin Auton Res 11(5):295-301

Charkoudian N, Joyner MJ (2004) Physiologic considerations for exercise performance in women. Clin Chest Med 25:247-255

Charkoudian N, Joyner MJ, Johnson CP, Eisenach JH, Dietz NM, Wallin BG (2005) Balance between cardiac output and sympathetic nerve activity in resting humans: role in arterial pressure regulation. J Physiol 568(Pt 1):315-321, doi:10.1113/jphysiol.2005.090076

Christou DD, Jones PP, Jordan J, Diedrich A, Robertson D, Seals DR (2005) Women have lower tonic autonomic support of arterial blood pressure and less effective baroreflex buffering than men. Circulation 111:494-498 
Evans JM, Ziegler MG, Patwardhan AR, Ott JB, Kim CS, Leonelli FM, Knapp CF (2001) Gender differences in autonomic cardiovascular regulation: spectral, hormonal, and hemodynamic indexes. J Appl Physiol 91 (6):2611-2618

Fleg JL, O'Connor F, Gerstenblith G, Becker LC, Clulow J, Schulman SP, Lakatta EG (1995) Impact of age on the cardiovascular response to dynamic upright exercise in healthy men and women. J Appl Physiol 78(3):890-900

Foss ML, Keteyian SL (1988) Physiological Basis of Exercise and Sport. McGraw Hill, Inc, New York, p 83

Fu Q, Witkowski S, Okazaki K, Lavine BD (2005) Effects of gender and hypovolemia on sympathetic neural resopnses to orthostatic stress. Am J Physiol Regul Integ Comp Physiol 289:R109-R116

Hart EC, Charkoudian N, Wallin BG, Curry TB, Eisenach JH, Joyner MJ (2009) Sex differences in sympathetic neural-hemodynamic balance: implications for human blood pressure regulation. Hypertension 53:571-576

Hart EC, Charkoudian N, Wallin BG, Curry TB, Eisenach J, Joyner MJ (2011) Sex and ageing differences in resting arterial pressure regulation: the role of the beta-adrenergic receptors. J Physiol 589(Pt 21):5285-5297, doi:10.1113/jphysiol.2011.212753

Higginbotham MB, Morris KG, Coleman RE, Cobb FR (1984) Sex-related differences in the normal cardiac response to upright exercise. Circulation 70(3):357-366

Johnson BD, Beck KC, Proctor DN, Miller J, Dietz NM, Joyner MJ (2000a) Cardiac output during exercise by the open circuit acetylene washin method: comparison with direct Fick. J Appl Physiol 88(5):1650-1658

Johnson BD, Beck KC, Proctor DN, Miller J, Dietz NM, Joyner MJ (2000b) Cardiac output during exercise by the open circuit acetylene wasin method: Comparison with direct fick. J Appl Physiol 88:1650-1658

Joyner MJ (2006) Counterpoint: the muscle metaboreflex does restore blood flow to contracting muscles. J Appl Physiol 100:358-360

Joyner MJ, Charkoudian N, Wallin BG (2008) A sympathetic view of the sympathetic nervous system and human blood pressure regulation. Exp Physiol 93:715-724

Katch V, Weltman A, Sady S, Freedson P (1978) Validity of the relative percent concept for equating training intensity. Eur J Appl Physiol Occup Physiol 39(4):219-227

Kneale BJ, Chowienczyk PJ, Cockcroft JR, Coltart DJ, Ritter JM (1997) Vasoconstrictor sensitivity to noradrenaline and NG-monomethyl-L-arginine in men and women. Clin Sci (Lond) 93(6):513-518

Kneale BJ, Chowienczyk PJ, Brett SE, Coltart DJ, Ritter JM (2000) Gender differences in sensitivity to adrenergic agonists of forearm resistance vasculature. J Am Coll Cardiol 36(4):1233-1238

Kuo LC, Bolli R, Thornby J, Roberts R, Verani MS (1987) Effects of exercise tolerance, age, and gender on the specificity of radionuclide angiography: sequential ejection fraction analysis during multistage exercise. Am Heart J 113(5):1180-1189

Lansley KE, Dimenna FJ, Bailey SJ, Jones AM (2011) A 'new' method to normalise exercise intensity. Int J Sports Med 32(7):535-541, doi:10.1055/s-0031-1273754

Narkiewicz K, Phillips BG, Kato M, Hering D, Bieniaszewski L, Somers VK (2005) Gender-selective interaction between aging, blood pressure, and sympathetic nerve activity. Hypertension 45:522-525

Ogawa T, Spina RJ, Martin WH 3rd, Kohrt WM, Schechtman KB, Holloszy JO, Ehsani AA (1992) Effects of aging, sex, and physical training on cardiovascular responses to exercise. Circulation 86(2):494-503

Proctor DN, Beck KC (1996) Delay time adjustments to minimize errors in breath-by-breath measurement of VO2 during exercise. J Appl Physio 81:2495-2499

Rowell LB (1993) Human Cardiovascular Control. Oxford niversity Press, New york

Sargent C, Scroop GC (2007) Plasma lactate accumulation is reduced during incremental exercise in untrained women compared with untrained men. Eur J Appl Physiol 101(1):91-96, doi:10.1007/s00421-007-0477-9

Schmitt JA, Joyner MJ, Charkoudian N, Wallin BG, Hart EC (2010) Sex differences in alpha-adrenergic support of blood pressure. Clin Auton Res 20(4):271-275, doi:10.1007/s10286-010-0061-y

Sealey JE (1991) Plasma renin activity and plasma prorenin assays. Clin Chem 37(10 Pt 2):1811-1819

Snyder EM, Beck KC, Dietz NM, Eisenach JH, Joyner MJ, Turner ST, Johnson BD (2006) Arg16Gly polymorphism of the \{beta\}2-adrenergic receptor is associated with differences in cardiovascular function at rest and during exercise in humans. J Physiol 571(Pt 1):121-130

Spina RJ, Ogawa T, Miller TR, Kohrt WM, Ehsani AA (1993) Effect of exercise training on left ventricular performance in older women free of cardiopulmonary disease. Am J Cardiol 71(1):99-104
Sudhir K, Elser MD, Jennings GL, Komesaroff PA (1997) Estrogen supplementation decreases norepinephrine-induced vasoconstriction and total body norepinephrine spillover in perimenopausal women. Hypertension 30(6):1538-1543

Sullivan MJ, Cobb FR, Higginbotham MB (1991) Stroke volume increases by similar mechanisms during upright exercise in normal men and women. Am J Cardiol 67(16):1405-1412

Wheatley CM, Snyder EM, Joyner MJ, Johnson BD, Olson TP (2013) Comparison of intra-arterial and manual auscultation of blood pressure during submaximal exercise in humans. Appl Physiol Nutr Metab 38(5):537-544, doi:10.1139/apnm-2012-0294

doi:10.1186/2193-1801-3-445

Cite this article as: Wheatley et al.: Sex differences in cardiovascular

function during submaximal exercise in humans. SpringerPlus 2014 3:445.

\section{Submit your manuscript to a SpringerOpen ${ }^{\odot}$ journal and benefit from:}

- Convenient online submission

- Rigorous peer review

- Immediate publication on acceptance

- Open access: articles freely available online

- High visibility within the field

- Retaining the copyright to your article

Submit your next manuscript at $\gg$ springeropen.com 